\title{
Aplicación web para la gestión de planes de desarrollo individual de enfermería en una unidad de nefrología
}

\author{
Francisca Medero Rubio, David Bejarano Álvarez, Piedras Alba Gómez Beltrán, Manuela Pérez Márquez, \\ Esperanza Garrido Sánchez
}

Hospital Juan Ramón Jiménez. Huelva

\section{Introducción:}

La gestión por competencias se perfila como una herramienta útil para desarrollar los distintos procesos de gestión de personas. Su principal objetivo es identificar la habilidad de los trabajadores para que consigan la máxima autonomía en el desarrollo de su trabajo, con el fin de potenciar y optimizar los resultados. El mapa competencial se considera fundamental en el análisis, la descripción del puesto de trabajo y la elaboración del perfil profesional, ya que permite establecer las competencias necesarias para el desempeño, las responsabilidades y los requerimientos de dicho puesto. Siguiendo el Modelo de Gestión por Competencias del Sistema Sanitario Público de Andalucía y a través de una herramienta creada por el Observatorio para la calidad de la formación en salud, que ofrece la posibilidad de la elaboración de planes de desarrollo individual, basados en itinerarios formativos, nos planteamos la necesidad de elaborar el Mapa de Competencias de la enfermera de la Unidad de Gestión Clínica de Nefrología de nuestro Hospital. Para ello, se creó un grupo de trabajo formado por cuatro enfermeras y un coordinador de grupo. A continuación, se presentó y explicó la herramienta web a todos los profesionales de enfermería. Posteriormente cada uno procedió a la elaboración de su Plan de Desarrollo Individual, y a partir de ahí se detectaron las necesidades formativas tanto a nivel individual como de la unidad. El Mapa de Competencias quedó constituido por 21 Buenas Prácticas y 97 Evidencias referidos a 14 competencias distintas. Se analizaron las distintas respuestas de todos los profesionales, referidos a cada una de las buenas prácticas con el nivel de logro para cada una de ellas. Todo ello nos ayudó a establecer el plan de necesidades de desarrollo, en función de las prioridades detectadas. En nuestro diseño, se consideró prioritario acciones formativas para las buenas prácticas "El/la profesional apoya y forma a las cuidadoras familiares principales sobre el desempeño de su rol y su propio cuidado" y "El profesional favorece la continuidad asistencial prestada a los pacientes, apoyándose en los registros de la historia de salud y en los informes de derivación, de consulta y de alta". Actualmente trabajamos junto con la Unidad de Formación para dar respuesta a estas áreas de mejora.

\section{Referencias Bibliográficas}

1. Modelo de Gestión de Planes de Desarrollo Individual (GPDI) en el SSPA. Conceptos claves. Estrategias para la Formación en Salud. Observatorio para la Calidad de la Formación en Salud. Agencia de Calidad Sanitaria de Andalucía. Lacceso 24 abril 2013]. Disponible en: http://www.juntadeandalucia.es/agenciadecalidadsanitaria/formacionsalud/ microsite/cms/es/gpdi/.

2. Herramienta para la Realización del Mapa de Competencias y Plan de Desarrollo Individual. [acceso 23 abril 2013]. Disponible en: www.saludinnova. com/practices/view/840/ 12-mayo-2011.

3. Guía para la elaboración de Mapas de Competencias. [acceso 23 abril 2013]. Disponible en: www. iavantefundación.com/portal3d/Actividad/consultoría/guía.pdf -Modelo de competencias laborales. [acceso 24 abril 2013]. Disponible en: http://www. arearh.com/psicologia/modelo_competencia.htm.

4. Omayda Urbina Laza C. Competencias de Enfermería para la seguridad del paciente. Revista Cubana de Enfermería. 2011:27(3) 239-247. 
5. ¿Cómo definen los profesionales de enfermería hospitalarias sus competencias asistenciales?" Juvé Udina, María Eulalia; Farrero Muñoz, Sara; Matud Calvo, Cristina; Monterde Prat, David; Fierro Barrabés, Gemma; Marsal Serra, R; et al. Nursing Ed esp [2007 ago-sep] 25 (7):50-61 [ consultado 24 de abril de 2013 ]. Disponible: http://www.doyma.es/nursing.

6. Elaboración de un mapa de competencias para las Enfermeras del Área Quirúrgica de Traumatología y Ortopedia. [acceso 24 abril 2013]. Disponible en: http://www.saludinnova.com/practices/view/987/.

7. Antoñanzas Baztán, Elena; Ferro Montiu, Mercedes. Innovación en la organización de una Unidad de Enfermería: Modelo Sinergia. Tesela. [Revis- ta en Internet] 2012;12. Disponible: http://www. index-f.com/tesela/ts12/ts9103.php.

8. Bazán Calvillo V, Gordillo Legido A. Análisis de desarrollo profesional por mapas de competencias. Evidentia 2006 sep-oct; 3(11). [consultado 15 de abril de 2013]. Disponible: http:// www.index-f.com/evidentia/n11/257articulo. php(ISSN:1697-638X).

9. Barquero González, Ana; León López, Rocío; Pascual Orts, Luis Miguel; Blasco Santamaría, Rosa $M^{a}$. El mapa de competencias para directivos de enfermería como herramientas de gestión y evaluación. Nursing. 2009; 27(09): 62-6 - vol.27 núm 09. 